\title{
Crise dos afetos: intimidade e cotidiano no cinema e na televisão
}

\author{
Patricia Colmenero Moreira de Alcantara \\ Fabíola Calazans
}

Resumo: Em um momento em que a intimidade é tema principal, tanto da programação televisiva quanto das salas de cinema, observa-se uma crise dos afetos, em que o risco de aprisionamentos subjetivos e de reificação se intensificam. Neste artigo, foram analisados dois objetos empíricos que privilegiam a vida cotidiana e a intimidade como tema, perpassando alguns territórios afetivos, entre eles, o filme Uma mulher é uma mulher, de Jean-Luc Godard, e a televisão contemporânea, em especial, o canal brasileiro GNT. Como conclusão, a trajetória do eu parece estar ameaçada pela mercantilização das performances afetivas.

Palavras-chave: intimidade; cotidiano; cinema; televisão; afetos.

Abstract: Affection crisis: privacy and everyday life in film and television - When intimacy is the main theme of both television programs and in movies theaters, an affection crisis is observed, in which the risk of subjective imprisonments and reification intensify. In this paper we analyze two empirical objects that emphasize the theme of everyday life and privacy, which pervade some affective territories, such as the film "A woman is a woman", of Jean-Luc Godard, and contemporary television, in particular the Brazilian television channel GNT. In conclusion, the trajectory of the self seems threatened by the marketing of affective performances.

Key words: privacy; everyday life; cinema; television; affections.

Episodicamente narrada nos folhetins de imprensa, a vida cotidiana ganhou visibilidade nos romances burgueses do século XIX, cujo realismo assegurou uma identificação cada vez mais intensa entre o leitor e seus heróis, entre imaginário e real. Não se restringindo ao romance, a vida cotidiana e seu indivíduo comum flanaram por entre os poemas e as poesias de Baudelaire, tendo suas pegadas apagadas por Edgar Allan Poe e, posteriormente, no século XX, por Bertolt Brecht. No final do século XIX, 
com a imagem em movimento e com o cinematógrafo dos irmãos Lumière, o indivíduo comum pôde ter sua feição imagética e movente projetada e, já no início do século XX, teve definitivamente seu cotidiano projetado com o cinema-verdade de Dziga Vertov. No século XXI, cinema e televisão se constituem em meio à estética do cotidiano e às narrativas que publicizam a intimidade, lugar privilegiado das manifestações afetivas ${ }^{1}$.

Os campos de estudos do cinema e da televisão são bem heterogêneos, pois se estabelecem justamente pela diversidade de saberes, experiências e afetos. Neste artigo, percorrem-se alguns espaços performáticos do cinema e da televisão, lugares que provocam outras territorialidades afetivas, estéticas e éticas. Entende-se que o cinema e a televisão seriam os espaços performáticos, por excelência, para mostrar o corpo, sendo o corpo "o local onde os eventos afetivos tomam forma" (DEL RIO, 2008, p. 4), o executor dos atos performáticos. Pensa-se que a própria imagem já é, em si, um corpo ${ }^{2}$.

Cinema e televisão são, pois, lugares que põem em xeque a intimidade, em um movimento que, no limite, poderia ser entendido como uma crise dos afetos. Esses espaços performático-afetivos são perpassados por afetos, no território do cinema indo do clichê romântico, vivido pelo happy end, ao cinema moderno - , e no território da televisão contemporânea, imersa no banal e na intimidade do âmbito privado. O filme Uma mulher é uma mulher (Une femme est une femme, 1961, França/Itália, 85 min), de Jean-Luc Godard, foi escolhido por exaltar o cotidiano e o universo privado de seus personagens, como o centro da discussão fílmica. Dentre todos os filmes do Godard, componentes do movimento moderno da Nouvelle Vague francesa, Uma mulher é uma mulher é o que melhor destaca os processos autoconscientes cinematográficos, em que os atores constantemente olham para a câmera, quebrando a quarta parede e instaurando um novo diálogo com o espectador, para além da mimesis, da representação, em direção à criação mais arrebatadora da performance. A televisão contemporânea e, em especial, o canal GNT, também foram selecionados por superexibirem o privado, midiatizando sentimentos e experiências vividos nos espaços da intimidade ou espaços do privado, os lugares onde se situam os afetos da vida íntima e cotidiana. A crise dos afetos é entendida, aqui, como a publicização massificada e mercantilizada da intimidade, dos sentimentos e das emoções vividas na vida cotidiana, explicitada na televisão e problematizada na cinematografia de Godard.

1 Neste trabalho, entendem-se manifestações afetivas e afetos a partir da leitura de Gilles Deleuze (2002) da Ética, de Baruch Espinosa (2002). Deleuze compreende o corpo como um punhado de forças e afetos que entram em contato com outras forças e afetos. Esses contatos são performáticos e criativos, desorganizando e desterritorializando conexões por um processo de automodificação, gerando a própria existência. É, portanto, afecção, a possibilidade de afetar e ser afetado. Dessa forma, afeto e emoção são noções diferentes, porém confluentes. Para Espinosa, o corpo não é mais algo funcional, é um corpo afetivo, que é definido pela sua capacidade de afetar e de ser afetado. Um corpo aberto, em contato com a vida e com o outro. Espinosa, assim como Nietzsche, propõe um plano de imanência em oposição a uma transcendência, como pretende uma tradição platônica.

2 A noção de filme como corporalidade data da metade dos anos 90, desprendendo a análise imagética da psicoanálise e da semiótica, que conduziam sempre para oposições binárias e ideológicas: sujeito/objeto, pensamento/emoção, etc. Com obras como The skin of film: Intercultural cinema, embodiment, and the senses (2000), de Laura Marks, institui-se a necessidade de experienciar a imagem de forma sensorial. 


\section{Perambulações da vida cotidiana e dos afetos no cinema}

Somente com a cultura de massa e com a sociedade do espetáculo que "a mercadoria ocupou totalmente a vida social" (DEBORD, 1997, p. 30), com poucos indivíduos sendo transformados em mercadoria-símbolo do capitalismo. Espetacularizados pelo cinema e eternizados como estrelas, em papéis de heróis e semideuses no Olimpo cinematográfico, os olimpianos do star system ${ }^{3}$ foram magnetizados no imaginário e no real, tornando-se os modelos ideais de cultura e de vida, seja de vida ordinária ou olimpiana, seja de natureza humana ou divina. As estrelas olimpianas eram os insumos do mecanismo de identificação e projeção, cultivado pela cultura de massa no século XX (MORIN, 1967; 1989). Engendrou-se um esquema de homogeneização subjetiva, em que a objetificação passa a ser desejada, já que ser o outro famigerado torna-se mais relevante do que ser si mesmo.

O cinematógrafo revelou não só diversas histórias e imagens imediatamente consumidas dentro do sistema da mercadoria, mas um universo de reflexão sobre essa cotidianidade revertida em intimidade na tela grande. O curta-metragem Kiss (1986), de Thomas Edson, mostrava uma mulher e um homem de cerca de 50 anos se beijando e foi um escândalo, chegando a levar a acusação de pornográfica à sétima arte. Em cerca de uma década, aquele beijo libidinoso se transformou no beijo angelical dos amantes, tornando o cinema hollywoodiano o cinema das narrativas amorosas. Cotidianos afetivos inundam os écrans e o amor é entendido como um afeto convertido em emoção, um afeto socializado. De acordo com a leitura espinosista de Elena Del Rio, "as emoções atualizam e concretizam a forma em que um corpo foi afetado" (DEL RIO, 2008, p. 5).

Entre 1917 e 1960, o cinema clássico impera como um cinema do amor, sendo o tipo amoroso predominante, o amor romântico, no qual se espera o final "e foram felizes para sempre". No celebrado Bonequinha de Luxo (Breakfast at Tiffany's, Blake Edwards, 1961, Estados Unidos, 115 min), apesar de Holly buscar um marido rico como solução para a sua tão desejada vida de luxo, termina por se apaixonar pelo vizinho, um escritor desempregado que se prostitui. Após ter conseguido se casar com um milionário brasileiro, ela renuncia ao seu sonho de extravagância e larga tudo para ficar com o paupérrimo Paul. Assim, não importam as limitações que o relacionamento lhe impuser ou o tipo de prisão que ele pode se tornar, o amor vence tudo. O herói clássico é um personagem motivado o suficiente para sempre resolver os problemas a ele imputados, conquistando sempre o amor de sua amada e o happy end ${ }^{4}$.

3 A expressão star system é empregada por Morin (1989) a fim de designar o sistema institucionalizado que manufatura as estrelas de cinema. Sendo um produto característico da civilização capitalista do século XX, em especial dos anos 1930-1960, a estrela "responde ao mesmo tempo a necessidades antropológicas profundas que se exprimem no mito e na religião", pois ela é a deusa como mercadoria em sua dupla face de "estreladeusa" e "deusa-mercadoria" (MORIN, 1989, p. 77).

4 O final pode ser também justo, como é o caso de Casablanca (Michael Curtis, 1942, Estados Unidos, 102 min), em que Rick não termina com Ilsa, mas salva o casamento dela com Victor, num grande ato altruísta. 
Há uma crença cega na força dos afetos, no amor e na felicidade. Os personagens têm poucas dimensões, questionamentos e ambiguidades. Tudo deve ser resumido a uma busca de autorrealização amorosa, cujas regras do jogo já estão postas e a garantia do sucesso sempre se apresenta no desfecho. Essa visão de mundo otimista torna-se falida após a Segunda Guerra Mundial. Com ela, a jornada do herói (e do amante) é afetada pela compreensão de que não é possível, com apenas força (física ou de vontade), resolver os seus conflitos. Há uma consciência da impotência do amante diante deste cenário flagelado e ocorre uma crise da imagem-ação: "essa crise é ligada à Segunda Guerra Mundial e à aparição concreta, entre as ruínas da guerra e a profusão de vencidos, espaços desconexos e personagens atormentados em situações diante das quais eles não têm reação" (RANCIÈRE, 2009, p. 12).

As crenças amorosas na felicidade, na clareza e simplicidade ficam abaladas e as dimensões que eram reprimidas pela objetividade da narrativa e da estética ganham espaço, edificando um amor ambíguo, incompleto, ilógico. O cinema clássico abre-se para o cinema moderno, com uma nova imagem que transparece essa realidade crítica do amor: a imagem-tempo. Gilles Deleuze (2007, p. 11) afirma que o cinema moderno "é um cinema de vidente, não mais de ação". É um cinema que estimula um novo tipo de contemplação, de uma percepção diferenciada e mais aguçada do que o cinema de simples encadeamentos de ações, que era o cinema clássico. Instaura-se um novo olhar, de uma nova imagem.

No cinema de vidente, é possível ver o que antes era oculto. O amor sai de sua prisão da caixa de ferramentas limitada e se expande em questionamentos, facetas e possibilidades. Tal alargamento provém da atual descrença na promessa de felicidade e eternidade romântica, afetando toda a filosofia do amor de maneira que os amantes não sabem mais o que fazer, o que esperar ou, até mesmo, como se mover. Dessa forma, a intimidade inunda a tela, se tornando o centro dos conflitos vividos pelos personagens, em detrimento do esforço heroico, que preenchia o espaço fílmico com grandes feitos e narrativas. Trata-se de um esvaziamento das ações presentes nas narrativas grandiosas em favor de um cinema mais minimalista, com elementos diegéticos reduzidos ao espaço do privado. No cinema moderno, o apaixonado percorre a cidade e perambula pelos lugares como perambula emocionalmente e diante da vida. Da mesma forma, o diálogo passeia pelos assuntos como quem vaga sem nenhum destino definido.

No filme de Jean-Luc Godard, Uma mulher é uma mulher, Alfred é um amigo do casal Angela e Émile, mas demonstra, claramente, ter interesse em ficar com ela. Ambos são incapazes de misturar suas motivações e o diálogo amoroso é incompleto e confuso. A incomunicação entre os temas, que se alternam sem conexão entre si, gera o fracasso do amor, perdido entre as perambulações mentais: 
"Eu te amo, isso não é importante?", diz Alfred. "Que engraçado... está mais escuro do que há uma hora atrás", responde Angela. Em seguida, Angela pergunta sobre o filho dele, mas Alfred afirma: "Não sei. Isso não é problema meu". Depois ele tenta de novo: "Não se importa que eu goste de você?", ao que Angela responde de forma evasiva: "Em francês, muda o significado se o adjetivo estiver antes ou depois do nome?".

Essa forma de balada apresenta amantes perdidos, confusos, indecisos, que não se interessam mais pela assertividade clássica, pela capacidade de conseguir bons resultados, mas erram sem rumo e sem objetivos, afundados no borrão insondável de seu interior. Na nova vidência, os apaixonados tropeçam e, como performers, esquecem suas falas e não sabem mais como responder às provas de amor.

Presente no filme, a autoconsciência da narrativa funciona como discussão metalinguística e afetiva, por exemplo, quando o casal interrompe uma briga para apresentar ao espectador sua "farsa", fazendo uma crítica bem explícita à mercantilização da intimidade. Os atores olham direto para a câmera, se inclinam como se fossem receber um rei e dizem: "Antes de representar a nossa pequena farsa, saudemos o respeitável espectador". Em outra cena, a quarta parede também é quebrada, explicitando e problematizando a exposição da intimidade. Nela, Angela está triste porque acabou de brigar com o namorado, que não quer ter filhos, e diz não se importar se ela os tiver com um amante. A personagem possui motivação para viver uma cena de sofrimento e o espectador compactua com ela. Porém, apesar da justificativa para uma interpretação realista, ela opta pela apresentação performática. Em interpretação teatral, encarna a mulher de uma peça, que sofre um amor não correspondido. Angela encena a própria vida, como se estivesse em um reality show, buscando a aprovação da audiência para a sua causa. Uma provocação crítica face à mercantilização da intimidade que, estilizada por Godard, confronta, à frente do seu tempo, a futura espetacularização do eu nas telas de televisão. Nesse filme, a criação é tanto afetiva quanto estética e narrativa, apostando em pontos de indeterminabilidade e confusão para minar as antigas estruturas, agregando novos territórios.

Com a saída do amor do território do clichê romântico, o cinema moderno propõe um tipo de amor mais questionador e obscuro, revelando de forma evidente o íntimo. Esse cinema põe em crise as manifestações afetivas da intimidade. Com um foco ampliado para o banal e o cotidiano, penetra-se a vida dos casais, a intimidade dos problemas. No filme analisado, o trivial é o espetáculo: as brigas, os confrontos entre homens e mulheres e as reconciliações. O prosaico é valorizado e "as situações cotidianas e mesmo as situaçõeslimite não se assinalam por algo raro ou extraordinário" (DELEUZE, 2007, p. 31).

O apartamento é o espaço da intimidade, onde estética e ética se misturam e se apresenta uma ética estetizada. A própria forma de viver, suas vulgaridades, o objeto comum, cozinhar - a partir de um cotidiano de clichês, emana o sublime no banal. 
A casa, o lar, é um reflexo direto dos estados de alma dos personagens, um álbum de memórias e o palco para as experiências íntimas. A casa é também refúgio, espaço que abriga a dualidade de habitar entre o interior e o exterior, sendo "uma espécie de meia caixa, metade paredes metade porta", esconderijo que "nos assegura um primeiro valor do ser: a imobilidade. Ela é o local seguro" (BACHELARD, 1988, p. 146). A casa é também um espaço performático de uma intimidade que não é apenas a repetição de costumes. Os habitantes podem se manifestar num processo espontâneo e inédito, performáticoafetivo. Como a personagem Angela, que vive um processo ambíguo de encenação, no qual nunca se sabe quando ela está se inventando ou se revelando.-

\section{A mercantilização dos afetos íntimos e cotidianos na televisão contemporânea}

Na banalidade, revela-se o espaço da intimidade, das conversas privadas e dos atos comuns. Porém, a crise dos afetos provoca não só novos encontros, mas também novas formas de mercantilização midiática desses afetos emergentes. A publicização e a exteriorização do privado, ou ainda, a hiperespetacularização do cotidiano e do banal já se alastraram pelas telas ao ponto de, diariamente, assistirmos à exposição da intimidade pela televisão. As intensas visibilidade e exibição da vida ordinária do eu nas telas impulsionam a emergência de diversas experiências da subjetividade contemporânea, ou seja, de modos de ser e estar no mundo ${ }^{5}$. Aquilo que, por tempos, foi interiorizado na esfera privada burguesa, bem como revelado e narrado em diários íntimos do século XIX, aparece, do interior para o exterior, em um movimento de visibilidade do eu, que projeta sua intimidade nas telas da cultura do espetáculo, seguindo a premissa de "aparecer para ser", pois "só é o que se vê" (SIBILIA, 2008, p. 25). Estamos vivendo a "era da altavisibilidade" e todo o "processo de produção de uma visibilização intensa e constante parece nos fascinar irresistivelmente" (PEREIRA, 2005, p. 64).

Em reality shows, as pessoas contam segredos e apresentam suas atividades diárias como escovar os dentes, tomar café ou, simplesmente, fazer nada. Com altos índices de audiência e de rentabilidade, as narrativas em ato dos reality shows consolidaram a incidência de visibilidade sobre a fala do indivíduo comum, bem como sobre suas narrativas íntimas e cotidianas. Com o crescimento acelerado da comercialização dos reality shows e sua vasta aceitação pela audiência nos anos 2000, a produção

5 Subjetividade é entendida aqui como os modos de ser e estar no mundo do nosso eu, os quais envolvem pensamentos e emoções mais pessoais sobre "quem nós somos" (WOODWARD, 2000, p. 55). Longe de um "sentimento de si", com dimensões fixas e estáveis, deu-se lugar a um sujeito histórico, que se observa ao se observar o mundo, ao sabor de um tempo histórico cuja função é ser agente absoluto de mudança (GUMBRECHT, 1998). A subjetividade é, pois, construída sob os contornos de dúvidas, incertezas e pluralidades das diversas experiências socioculturais contemporâneas. De acordo com Sibilia (2008, p. 16), "a subjetividade não é algo vagamente imaterial que reside 'dentro' de você" é, pois, sobretudo, "embebida em uma cultura intersubjetiva", visto que aquilo que somos também é modulado por nossas experiências, interações com os outros e com o mundo. 
televisiva contemporânea firmou-se em uma era cuja pedra-de-toque é a visibilidade da intimidade do mundo cotidiano do indivíduo comum. Sucesso genuíno dos reality shows na televisão mundial, o Big Brother convoca os olhares a ver e avaliar a exibição da intimidade dos anônimos nas telas (MEHL, 1996; FECHINE, 2009; CAMPANELLA, 2009). Como consequência de seu modelo fortunado, o reality show tornou-se formato de referência para outros programas, de modo que a exibição da vida privada tem, cada vez mais, se acentuado na televisão contemporânea, com seus produtos de amplo sucesso de audiência, como game show (competição entre pessoas desconhecidas dentro de um ambiente controlado), programas sobre transformações pessoais e de estilo de vida (aparência, práticas rotineiras, etc.) ou materiais (casa, jardim, restaurante, etc.), programas de troca de vida (troca de esposas, troca de chefe, etc.) e de concurso de talentos; todos subgêneros da "TV-Realidade" (NUNN, 2009).

Tais produções de sentido da televisão contemporânea superexibem a intimidade do indivíduo comum e, muitas vezes, se vestem de uma aura de unicidade, a qual é convertida em um valor mercadológico, dando a sensação falaciosa de serem originais e inéditas; no entanto, elas seguem uma tendência já instaurada pelos modos de ver o comum e o cotidiano nos folhetins, nas fotografias, no jornal, no rádio, no cinema, na televisão e, mais recentemente, nos computadores, nos telefones móveis, etc.

Nesse cenário, a intimidade do outro parece ser apenas um local intermediário entre um dia de trabalho e outro, acessível por um click ou uma zapeada ao chegar em casa. Mas será isto, de fato, a intimidade: os meios de comunicação como extensão do vivido no âmbito privado? Uma indagação sobre os afetos que depende da compreensão acerca do mundo das narrativas íntimas e pessoais, que fluem de modo furtivo pelas programações televisivas contemporâneas, por meio da exibição de assuntos da vida privada dos sujeitos, com tom de cuidado, acolhimento e aconselhamento. Segundo França (2009), o traço de personalismo e intimidade é um dos aspectos marcantes da televisão brasileira contemporânea, que reverencia as experiências de vida e as realizações afetivas dos sujeitos comuns. As visibilidades do cotidiano e da intimidade dos indivíduos comuns são a espinha dorsal da televisão brasileira contemporânea, que se perfaz flexível participando cada vez mais da vida sociocultural contemporânea. Essa televisão corrói as fronteiras entre o público e o privado (BIRESI; NUNN, 2005) e se apresenta de uma forma mais popular e participativa.

Eis a "televisão da intimidade", que "vem reforçar o duplo processo de privatização do espaço público e de publicização do espaço privado", conforme definiu Dominique Mehl (1996, p. 12, tradução nossa). Para Mehl, a "televisão da intimidade" é caracterizada como relacional; o cerne do seu modelo é a comunhão entre emissores e receptores; seus valores são a compreensão, a conivência e a cumplicidade. Com base na expressão das emoções e dos testemunhos de indivíduos comuns e anônimos, a televisão da intimidade apresenta os afetos e valoriza a mostração em um mundo cuja sociedade do espetáculo 
preocupa-se, cada vez mais, em revelar a intimidade do eu. De acordo com Mehl (1996), a televisão da intimidade, ou ainda, a televisão compassiva e confessional, exibe a expressão mais íntima dos afetos dos indivíduos comuns e revela mudanças sociais significativas, de modo que pode ser analisada como um sintoma da vida social contemporânea.

Com efeito, a experiência televisiva tem se tornado ainda mais envolvente no que diz respeito aos afetos que estão submergidos no processo de produção de subjetividade. Essa televisão mais personalista e íntima da vida diária tem introduzido diversos programas do tipo "filantrópico" (FREIRE FILHO, 2009), coerentes à "cultura terapêutica" contemporânea (BIRESI; NUNN, 2005), cujos indivíduos confessam suas experiências afetivas e buscam aconselhamento no bios midiático para a constituição de suas subjetividades. Destaca-se a série de ficção do canal brasileiro GNT, dirigida por Selton Mello, Sessão de Terapia, uma versão da série israelense Be Tipul, criada pelo psicanalista israelita Hagai Levi, com sucesso de audiência nas adaptações para cerca de trinta países. No Brasil, houve três temporadas até 2014, cujas exibições no GNT aconteceram de segunda a sexta, às 22h30. Ambientada no consultório de psicanálise, que é também a casa de Theo Cecatto, um psicoterapeuta de meia-idade casado com Clarice, a série narra o cotidiano das consultas, bem como as histórias íntimas dos pacientes e do próprio Theo. Toda sexta-feira, o psicoterapeuta se revela para Dora, uma psicóloga e orientadora sênior que assume o papel de sua supervisora. No consultório de Dora, o psicoterapeuta torna-se paciente e expõe problemas de sua vida pessoal e de seus pacientes.

Durante as consultas, Theo conduz os pacientes a revelarem seus medos e suas inseguranças, de modo que, a cada sessão, torna-se visível um pouco mais sobre a trama íntima de cada paciente. Nessa série, assuntos reservados são postos explicitamente não como pano de fundo, mas como tessitura central das narrativas dos personagens, em um movimento de revelação subjetiva. Com efeito, o olhar voyer do telespectador assiste àquilo que outrora deveria ser guardado no âmbito privado de uma consulta.

Como exemplo da exibição da vida íntima e do interesse pela publicização do privado na televisão contemporânea, destaca-se o primeiro episódio da personagem Júlia Rebelo, uma médica anestesista que vive conflitos de relacionamento com o noivo e se apaixona por Theo. Depois de uma noite de brigas com o noivo, André, Júlia conta ter saído para beber com a amiga e ter feito "coisas horríveis", inclusive ficou cerca de 4 horas na frente da casa-consultório do Theo esperando o horário da consulta. Ela conta que foi abordada por um desconhecido, cuja investida despertou sua curiosidade: "A tristeza te cai tão bem", ele disse. Júlia conta a Theo que, em um determinado momento, o homem perguntou se ela queria ir a algum outro lugar. Ela disse que sim, ao banheiro. Ela foi e ele a seguiu.

Júlia: (...) Foi aí que eu percebi no que que o cara estava pensando. (...) Me deu medo. Mas aí eu lembrei que eu nunca tinha transado com ninguém no banheiro. E eu ia casar com o André sem nunca ter transado com ninguém num banheiro público? Eu decidi fazer isso... Por mim. 
Theo: Por você ou para machucar o André?

Júlia: Pela experiência. Minha experiência. Uma mulher pressionada a casar assim, com tanta coisa pra viver, experimentar? Ele fechou a porta, levantou minha saia... De repente começou a me dar um tesão. Tô achando isso meio forte pra você... É Theo?

Theo: Não, não, de maneira nenhuma.

Júlia: Se for, me diz. Isso te excita? Ele abriu o zíper, abaixou a calça (...)

Essa revelação em minúcias da vida íntima e cotidiana dos personagens é o cerne da série Sessão de Terapia, que superexibe sentimentos e emoções vividos nos espaços do privado, a fim de envolver a escopofilia dos telespectadores. As midiatizações das experiências e dos sentimentos reforçam o tom íntimo operado pela televisão contemporânea, que espetaculariza o indivíduo, exibindo, sobretudo, seu corpo e seus afetos.

Diante desse quadro de exposição do eu nas telas, impera o regime da escopofilia do ver e do ser visto, cujo ímpeto é tornar tudo visível, tudo aparente ${ }^{6}$. De modo peculiar e inaudito, na televisão contemporânea, com seus programas reveladores do cotidiano e da intimidade do sujeito comum, notam-se muitos (telespectadores) assistindo a poucos (os sujeitos que aparecem na tela), configurando um regime de sinoptismo (MATHIESEN, 1997; LYON, 2010). Ao revisitar a noção de panóptico de Jeremy Benthan, empreendida por Foucault (2002) para analisar a sociedade disciplinar e de controle com seus dispositivos de vigilância, Thomas Mathiesen (1997) sugere uma perspectiva complementar à visão do panoptismo foucaultiano, pois abrange a mídia de massa e as tecnologias da informação e da comunicação, não se restringindo ao âmbito da prisão, do manicômio, da sociedade disciplinar, etc. As duas metáforas operam juntas no panóptico-sinóptico (MATHIESEN, 1997; LYON, 2010) sob uma lógica na qual muitos espectadores, sem que sejam vistos, assistem à exibição da vida privada de poucos indivíduos.

A televisão da intimidade é coerente à sociedade contemporânea na qual impera o regime do panóptico-sinóptico, da espetacularização do eu, do ver e do ser visto, da escopofilia que agencia o olhar da sociedade espectadora, sua visibilidade e sua vigilância coletiva. Ao pensar as reconfigurações do estatuto do olhar, Fernanda Bruno (2005) propõe a categoria "olho público", de modo a caracterizar uma ordem de exposição e de aparência da performance vivida no mundo contemporâneo. A autora analisa as reorganizações do espaço público e privado no sentido de mostrar como a vida privada dos homens comuns tornou-se objeto privilegiado de visibilidade desse "olho público", que é "ao mesmo tempo de todos e de ninguém" (BRUNO, 2005, p. 56).

6 A partir do regime escópico estudado por Christian Metz (1982) e, posteriormente, retomado por Martin Jay (1988), compreende-se regime de escopofilia como aquele cuja visualidade sobre a observação é alimentada pelo voyerismo, pelo desejo de ver, pelo amor por olhar. 
A partir desse panorama, pode-se dizer que os princípios ordenadores da televisão contemporânea são a proximidade da televisão com a vida diária, o interesse pelo ver e pelo ser visto em um regime sinóptico, a exibição da intimidade e do cotidiano e a mostração de narrativas - revelações, confissões e testemunhos - de indivíduos comuns em primeira pessoa. As produções de sentido acerca da visibilidade do cotidiano e da intimidade do sujeito comum são, ao mesmo tempo, suporte e instrumento, para a construção dos produtos midiáticos e para a constituição das subjetividades contemporâneas.

\section{Considerações finais}

A intimidade é um espaço da vida que não está diretamente conectado à estrutura produtiva, apesar de ser cooptada a todo tempo pelos produtos culturais. Mas, nem por isso, a intimidade é algo irrelevante ou um espaço de menor importância. Ela é, sobretudo, um espaço poético, no qual podem ocorrer encontros afetivos e, talvez, um reencantamento do mundo, em que o habitar "é já construir, ter a ilusão humana de pertencer e permanecer por pouco que seja" (LOPES, 2007, p. 89), traduzindo-se como uma alternativa ética e estética.

No objeto analisado, Uma mulher é uma mulher, de Jean-Luc Godard, a intimidade é um espaço de resistência, na medida em que critica a espetacularização e a mercantilização da intimidade. Uma leitura que problematiza a crise dos afetos em tempos de reality shows. A própria forma de viver, suas banalidades, o ordinário e o cotidiano, um objeto comum, o ato de cozinhar, de dormir e de acordar, tudo isso é também campo de potência para o poético. A intimidade estética que afirma "que o nosso mundo não é 'totalmente administrado, colonizado pela reificação'” (ibidem, p. 84), que a existência é algo além da produção, da eficiência, do universo do trabalho.

Na contramão da crítica poética está a abordagem mercantilista da televisão contemporânea, que se apropria da intimidade como um produto altamente rentável, face a um regime escópico, que tudo quer ver. Nas correntes de realidade que se entrecruzam no canal GNT, a todo o momento, somos convocados à escopofilia da intimidade e dos espaços de afetividade, mesmo que nem sempre dilatem nossa potência para o agir. Por meio de imagens, textos e sons, esses espaços de afetos e intimidades são postos nas telas como lócus para nossas condutas de ser e estar no mundo, segundo as quais a felicidade, em trajes de sucesso, é o alvo da autorrealização empreendedora da trajetória do eu.

Não há como negar: nosso cotidiano e nossa vida privada são urdidos pelos imperativos de uma cultura dinamizada por modos performáticos de viver, muito desejados, mas quase sempre inalcançáveis. Na eterna esperança por um ser outro, em meio à fuga desses imperativos, encontramos os afetos como uma forma de ampliarmos os espaços do devir de emoções, de acasos, enfim, de mudanças. 
Fabíola Calazans é doutora em comunicação social pelo Programa de Pós-Graduação em Comunicação Social da Universidade de Brasília, na linha Imagem e Som. Mestre em Comunicação Social pelo Programa de Pós-Graduação em Comunicação do Instituto de Artes e Comunicação Social da Universidade Federal Fluminense, na linha Tecnologias da Comunicação e da Informação. Professora ajunta e pesquisadora do Departamento de Audiovisuais e Publicidade, da Faculdade de Comunicação da Universidade de Brasília.

fabiola.calazans@gmail.com

Patrícia Colmenero Moreira de Alcantara é doutoranda em cinema na linha de Imagem em Som pela Universidade de Brasília. Mestra pela linha de Imagem e Som (UnB). Possui graduação em Letras - Português pela mesma universidade e é docente da faculdade IESB.

belamagnolia@gmail.com

\section{Referências}

BACHELARD, Gaston. Poética do espaço. São Paulo: Martins Fontes, 1988.

BIRESI, Anna; NUNN, Heather. Reality TV: Realism and Revelation. London: Wall Flower Press, 2005.

BRUNO, Fernanda. Quem está olhando? Variações do público e do privado em weblogs, fotologs e reality shows. Contemporânea, vol. 3, n. 2, p. 53-70, jul./dez. 2005. Disponível em: <http://www. portalseer.ufba.br/index.php/contemporaneaposcom/article/view/3461 >. Acesso em: 12 fev. 2013.

CAMPANELLA, Bruno. Visões do cotidiano: indivíduo e sociedade no Big Brother Brasil. In: FREIRE FILHO, João (Org.). A TV em transição: tendências de programação no Brasil e no mundo. Porto Alegre: Sulina, 2009, p. 171-194.

DEBORD, Guy. A sociedade do espetáculo. Rio de Janeiro: Contraponto, 1997.

DEL RIO, Elena. Deleuze and the cinemas of performances: powers of affection. Edinburgh: Edinburgh University Press, 2008.

DELEUZE, Gilles. A imagem-tempo: cinema 2. São Paulo: Brasiliense, 2007.

Espinosa: filosofia prática. São Paulo: Escuta, 2002.

ESPINOSA, Baruch. Ética: demonstrada à maneira dos geômetras. São Paulo: Martin Claret, 2002.

FECHINE, Yvana. A programação da TV no cenário de digitalização dos meios: configurações que emergem dos reality shows. In: FREIRE FILHO, João (Org.). A TV em transição: tendências de programação no Brasil e no mundo. Porto Alegre: Sulina, 2009. p. 139-170. 
FRANÇA, Vera V. A televisão porosa: traços e tendências. In: FREIRE FILHO, João (Org.). A TV em transição: tendências de programação no Brasil e no mundo. Porto Alegre: Sulina, 2009. p. 27-52.

FREIRE FILHO, João. Renovações da filantropia televisiva: do assistencialismo populista à terapia do estilo. In: (Org.). A TV em transição: tendências de programação no Brasil e no mundo. Porto Alegre: Sulina, 2009. p. 53-88.

GUMBRECHT, Hans Ulrich. Modernização dos sentidos. São Paulo: Ed. 34, 1998.

JAY, Martin. Scopic Regimes of Modernity. In: FOSTER, Hal (Ed.). Vision and Visuality. Seatle: Bay Press, 1988, p. 3-23.

LOPES, Denilson. A delicadeza: estética, experiência e paisagens. Brasília: UnB/Finatec, 2007.

LYON, David. 11 de setembro, sinóptico e escopofilia: observando e sendo observado. In: BRUNO, Fernanda; KANASHIRO, Marta; FIRMINO, Rodrigo (Orgs.). Vigilância e visibilidade: espaçO, tecnologia e identificação. Porto Alegre: Sulina, 2010. p, 115-140.

MARKS, Laura. The skin of film: Intercultural cinema, embodiment, and the senses. Durhan, N.C: Duke University Press, 2000.

MATHIESEN, Thomas. The viewer society: Michel Foucault's "panopticon" revisited. Theoretical Criminology, v. 1, no 2, p. 215-234, mai. 1997. Disponível em: <http://tcr.sagepub.com/ content/1/2/215.full.pdf+html>. Acesso em: 5 jan. 2013.

MEHL, Dominique. La télévision de I' Intimité. Paris: Seuil, 1996.

METZ, Christian. The Imaginary Signifier: Psychoanalysis and the Cinema. Bloomington: Indiana University Press, 1982.

MORIN, Edgar. As estrelas: mito e sedução no cinema. Tradução Luciano Trigo. $3^{a}$. ed. Rio de Janeiro: José Olympio, 1989.

Cultura de massas no século XX. Rio de Janeiro: Editora Forense, 1967.

NUNN, Heather. Programas voltados para o lar e para a propriedade: transformando a TV factual popular. In: FREIRE FILHO, João (Org.). A TV em Transição: tendências de programação no Brasil e no mundo. Porto Alegre: Sulina, 2009. p. 89-110.

PEREIRA, Carlos Alberto Messeder. Cultura do corpo em contextos de alta visibilidade. In: PEREIRA, Carlos Alberto Messeder; HERSCHMANN, Micael (Org.). Mídia, Memória \& Celebridades. 2. ed. Rio de Janeiro: E-Papers Serviços Editoriais, 2005. p. 63-72.

RANCIÈRE, Jacques. De uma imagem à outra. Deleuze e as eras do cinema. Intermídias. 9 ed., ano 5. 2009.

SIBILIA, Paula. O show do eu: a intimidade como espetáculo. Rio de Janeiro: Nova Fronteira, 2008.

WOODWARD, Kathryn. Identidade e diferença: uma introdução teórica e conceitual. In: SILVA, Tomaz Tadeu da (Org.). Identidade e diferença: a perspectiva dos estudos culturais. Petrópolis, RJ: Vozes, 2000. p. 7-72. 